\title{
ANÁLISE MULTIVARIADA DE ATRIBUTOS PEDOLÓGICOS E FITOSSOCIOLÓGICOS APLICADA NA CARACTERIZAÇÃO DE AMBIENTES DE CERRADO NO NORTE DE MINAS GERAIS ${ }^{1}$
}

\author{
Luciano de Oliveira Toledo², Lúcia Helena Cunha dos Anjos ${ }^{3}$, Wanderson Henrique do Couto ${ }^{3}$, João \\ Roberto Correia ${ }^{4}$, Marcos Gervasio Pereira ${ }^{3}$ e Maria Elizabeth Fernandes Correia ${ }^{5}$
}

\begin{abstract}
RESUMO - O Cerrado é uma das principais regiões de expansão agropecuária do país, entretanto a fragilidade dos seus ecossistemas restringe a capacidade de suporte a muitas das atividades agrícolas e compromete a preservação da sua biodiversidade. O objetivo deste estudo foi definir padrões locais de características edáficas e vegetacionais, em uma sub-bacia em Rio Pardo de Minas (MG), como base para o planejamento local de uso sustentável. Para tal, foram utilizadas técnicas de levantamento fitossociológico e de solos associadas à análise estatística multivariada, dendrograma e análise de componentes principais, de forma a correlacionar distribuição espacial de grupos de espécies e atributos edáficos. Os resultados indicaram a ordenação dos ambientes em dois grupos, em função da natureza dos materiais de origem: arenítico-quartzítico e sedimentos argilo-arenosos e argilosos. A seleção de variáveis pela análise multivariada foi capaz de discriminar os ambientes representados no levantamento fitossociológico. Os padrões identificados pelos agricultores corresponderam, em geral, às variações nos parâmetros florísticos e fitossociológicos e aos atributos edáficos, entre estes a densidade absoluta, a área basal e o índice de diversidade; as frações granulométricas foram determinantes na diferenciação dos ambientes.
\end{abstract}

Palavras-chave: Fitossociologia de Cerrado, solos florestais e manejo florestal.

\section{MULTIVARIATE ANALYSIS OF PEDOLOGICAL AND PHYTOSOCIOGICAL ATTRIBUTES APPLIED TO CHARACTERIZATION OF CERRADO ENVIRONMENTS IN NORTH OF MINAS GERAIS STATE, BRAZIL}

\begin{abstract}
The Cerrado is one of the main Brazilian expanding regions for agriculture, but the fragility of its ecosystems limits the support capacity for agriculture activities, jeopardizing the preservation of its biodiversity. The objective of this study was to define local patterns of edaphic and vegetation characteristics, of a small watershed in Rio Pardo de Minas municipality (Minas Gerais State, Brazil), as the basis for the sustainable planning for local usage. For such, techniques of phytosociological survey and soils were applied and associated to multivariate statistical procedures, dendrogram and PCA, in order to correlate the spatial distribution of groups of species with soil attributes. The results showed the classification of the environments into two groups, based on the nature of parent materials: arenitic-quartzitic and sandy-clayey and clayey sediments. The selection of variables using the multivariate analysis was able to discriminate the environments represented in the phytosociological plots. The patterns identified by the local farmers corresponded, in general, to the variations in the floristic and phytosociological parameters and edaphic attributes. The absolute density, basal area, Shannon index and the granulometric fractions were the determinant parameters in the differentiation of the environments.
\end{abstract}

Keywords: Cerrado phytosociology, forest soils and forestry management.

\footnotetext{
${ }^{1}$ Recebido em 05-11-2007 e aceito para publicação em 23.06.2009.

${ }^{2}$ Instituto Federal de Educação, Ciência e Tecnologia do Espírito Santo, Santa Teresa, ES - Brasil. E-mail: <ltoledo@ifes.edu.br>.

${ }^{3}$ Universidade Federal Rural do Rio de Janeiro, Departamento de Solos, Campus. Seropedica, RJ - Brasil. <lanjos@ufrrj.br>, <whcouto@gmail.com>e <gervasio@ufrrj.br>.

${ }^{4}$ Empresa Brasileira de Pesquisa Agropecuária, Centro de Pesquisa Agropecuária dos Cerrados, Planaltina. Brasilia, DF - Brasil. E-mail: <jrccinco@gmail.com>.

${ }^{5}$ Empresa Brasileira de Pesquisa Agropecuária, Centro Nacional de Pesquisa de Agrobiologia. Seropedica, RJ - Brasil. E-mail: <ecorreia@cnpab.embrapa.br>.
} 


\section{INTRODUÇÃO}

A manutenção da biodiversidade dos biomas da região central do Brasil, Cerrado e parte da Caatinga depende da relação entre o homem e o ambiente. A fragilidade desses ecossistemas restringe a sua capacidade de suporte a muitas das atividades humanas. No entanto, a expansão agropecuária elegeu o Cerrado como uma das principais regiões de produção do país, com implantação de culturas importantes para o agronegócio, como soja, bovinocultura de corte e eucalipto (ALVES, 2005).

Ambientes naturalmente frágeis e a intensa exploração agrícola têm acentuado a degradação dos ecossistemas, através da perda da capacidade produtiva das terras; de alterações indesejáveis no regime hídrico, principalmente na velocidade e forma de infiltração de água no solo, responsáveis pela recarga do lençol freático e regulação da vazão dos rios; do aumento de processos erosivos; e da perda de biodiversidade (GRIFFTH e TOY, 2005). A destruição dos ecossistemas que constituem o Cerrado continua de forma acelerada. Um estudo recente, que utilizou imagens do satélite MODIS do ano de 2002, concluiu que 55\% do Cerrado já foram desmatados ou transformados pela ação humana (MACHADO et al., 2004).

O Cerrado constitui um mosaico de paisagens, predominantemente ocupado por fisionomias de savanas estacionais sobre solos profundos e bem drenados das chapadas, cobrindo mais de dois terços de terras recortadas por estreitos corredores de florestas mesofíticas perenifólias ao longo dos rios (matas de galeria), ladeados por savanas hiperestacionais de encosta (campos úmidos) ou substituídos por brejos permanentes (veredas). Esse padrão é interrompido por tipologias vegetais de savanas estacionais de altitude (campos rupestres), savanas estacionais em solos rasos (campos litólicos), florestas xeromórficas semidecíduas (cerradões), florestas mesofíticas de planalto (matas de interflúvio), florestas baixas xeromórficas decíduas em solos arenosos (os carrascos) e outras (DIAS, 1996; RIBEIRO e WALTER, 2001). O Cerrado é composto por tipologias vegetacionais adaptadas aos solos com altos teores de alumínio e distróficos, predominando as classes Cambissolos, Latossolos e Neossolos Quartzarênicos.

A vegetação nativa, indivíduos ou comunidades são indicadores de condições edáficas (DREGNE, 1976). A vegetação reflete o efeito de atributos, como: textura, profundidade, disponibilidade de nutrientes e outros (DREGNE, 1976). A produtividade de fitomassa é um indicador de estresse e degradação, e sua avaliação no estrato arbóreo-arbustivo é importante no inventário florestal. Porém, a mensuração por formas destrutivas é trabalhosa e demanda tempo (ACCIOLY e OLIVEIRA, 2004). Nesse contexto, a modelagem da produtividade de fitomassa por meio de indicadores secundários, de obtenção mais fácil, é uma abordagem a ser considerada.

O manejo das terras influência diretamente a sua resposta ambiental. Sistemas de cultivo ou de uso de terras que não considerem a capacidade de suporte dos sítios podem levar os ecossistemas a estádios de degradação irreversíveis (ACCIOLY e OLIVEIRA, 2004). Entre outros fatores, a sustentabilidade do manejo florestal depende da taxa de regeneração da floresta após o corte, que é influenciada pela disponibilidade dos nutrientes, a qual é função do ciclo hidrológico, que regula tanto a disponibilidade de nutrientes quanto os processos de transferência dentro do sistema solo-planta-atmosfera (FERREIRA et al., 2004).

A ordenação dos ambientes, segundo características naturais, e a adequação da aptidão das terras constituem estratégia para diminuir impactos ambientais e conhecer o potencial de áreas de Cerrado. O objetivo deste estudo foi definir padrões locais de características edáficas e vegetacionais em uma sub-bacia no Município de Rio Pardo de Minas (MG), como base para o planejamento local de uso sustentável desses ambientes.

\section{MATERIAL E MÉTODOS}

\subsection{Caracterização da área}

O Município de Rio Pardo de Minas localiza-se no Norte do Estado de Minas Gerais, entre os paralelos $14^{\circ}$ e $18^{\circ} \mathrm{S}$ e os meridianos de $41^{\circ}$ e $46^{\circ} \mathrm{W}$ de Greenwich. A região Norte de Minas está situada numa faixa extensa do contato entre o Cerrado e a Caatinga (DAYREL, 1998). O município tem uma área de $3.118 \mathrm{~km}^{2}$, onde habitam cerca de 27 mil pessoas, das quais $10 \mathrm{mil} \mathrm{se}$ encontram em área urbana e 17 mil no meio rural (SEBRAEMG, 2003).

Entre as comunidades do município foi escolhida a sub-bacia Água Boa 2, que tem os seguintes: limite norte $-15^{\circ} 27^{\prime} 17,94^{\prime}$ 'S e $42^{\circ} 25^{\prime} 13,39^{\prime}$ 'W; limite sul $-15^{\circ} 32^{\prime} 37,91^{\prime \prime} \mathrm{S}$ e $42^{\circ} 27^{\prime} 40,97^{\prime \prime} \mathrm{W}$; limite leste - 
$15^{\circ} 28^{\prime} 21,42^{\prime \prime}$ 'S e $42^{\circ} 24^{\prime} 16,29^{\prime \prime}$ 'W; e limite oeste $15^{\circ} 29^{\prime} 41,87^{\prime \prime}$ S e $42^{\circ} 28^{\prime}$ '54,18' 'W (Datum Córrego Alegre).

A comunidade escolhida era, até então, piloto para estudos etnocientíficos, na microbacia do córrego Água Boa. A área foi escolhida pela expressão de solos e ambientes de Cerrado associada a uma comunidade de agricultores familiares que pouco utilizavam insumos industriais na produção agrícola. A comunidade Água Boa 2 é uma das 96 em Rio Pardo de Minas. Amicrobacia possuía cotas, que íam de 828 a 1.014 m e uma área de 5.197 ha. Eram 81 residências, com cerca de 400 moradores. A maioria dos chefes de família possuía entre 25 e 55 anos, com $40 \%$ da população com menos que 18 anos de idade $\mathrm{O}$ tamanho aproximado das propriedades era de 15 ha, numa média de 3 ha de área agricultável por família (CORREIA, 2005).

O clima é caracterizado por transição ecogeográfica entre o sudeste e o nordeste, passando de subúmido para semiárido, com ecótipos de Cerrado e Caatinga e formações de transição. De acordo com Köppen, o clima predominante é o Aw, de inverno seco e verão chuvoso. O mês mais frio tem média maior que $18{ }^{\circ} \mathrm{C}$ e a estação mais seca, precipitação menor que $60 \mathrm{~mm}$. Uma pequena área tem clima $\mathrm{Cwa}$, com temperaturas médias menores do que $18{ }^{\circ} \mathrm{C}$ no mês mais frio (EMBRAPA/SNLCS, 1979). Cerca de 20\% do Município de Rio Pardo de Minas é de relevo plano, $60 \%$ ondulado e $20 \%$ montanhoso. A altitude máxima, na Serra do Espinhaço, é de $1.790 \mathrm{~m}$ e a mínima de $830 \mathrm{~m}$, na foz do rio São João do Paraíso (SEBRAE-MG, 2003). A vegetação regional é de Cerrado, com tipologias vegetacionais afins (EMBRAPA/SNLCS, 1979). Ao leste ocorrem florestas subcaducifólias e caducifólias, alternadas com transição floresta/caatinga, e inclusões de Caatinga e Cerrado. Aoeste ocorre caatinga hiperxerófila e,ou, formações rupestres, margeando a Serra do Espinhaço.

Rio Pardo de Minas está situado na área de ocorrência de três formações geológicas: o pré-cambriano B (3.800 a $2.500 \mathrm{Ma}$ ), representado pelo Supergrupo Espinhaço (litologia de quartzitos, alguns siltitos, filitos e xistos); pré-cambriano C (1.000 a $570 \mathrm{Ma})$, representado pelo Supergrupo São Francisco (Grupo Macaúbas, formado a partir de espessa sedimentação gravitacional de fluxo de detritos e turbiditos); e recobrimentos (65 a 5,7 Ma) de materiais arenosos, areno-argilosos, argilo-arenosos e argilosos, referidos ao Terciário (SEBRAE-MG, 2003).
Na sub-bacia Água Boa 2 se encontram solos com influência de materiais arenítico-quartzíticos (áreas mais elevadas de chapadas - acima de 950 $\mathrm{m}$ de altitude - e alguns solos formados a partir de sedimentos fluviais - Neossolos Flúvicos e Cambissolos Flúvicos) ou solos originados de materiais sedimentares de texturas média, argilo-arenosa ou argilosa (latossolos). O primeiro conjunto resulta de materiais do pré-cambriano (B e C) e tem grande variabilidade e complexidade. O segundo grupo é oriundo de recobrimentos de sedimentos da Era Cenozóica (períodos Terciário e Quaternário - 65 a 0,01 Ma) e predomina nas áreas intensamente cultivadas ou manejadas em regime de extrativismo, pela comunidade (CORREIA et al., 2007).

\subsection{Amostragem e coleta de dados}

Diante da variabilidade encontrada em campo, foi necessário adotar critérios para escolha das áreas amostrais, sendo os principais critérios adotados: a) prévia identificação das principais fitofisionomias, em caminhamentos transversais e com a participação de membros da comunidade; b) classe de solo; e c) boas condições de acesso.

Com isso foram instaladas 10 parcelas amostrais de $50 \times 20 \mathrm{~m}$, sendo cada uma delas subdivididas em cinco subparcelas. A alocação dessas parcelas foi orientada pelo ponto de vista dos informantes-chave da comunidade, obtido através de entrevistas semiestruturadas, com a interpretação dos critérios de seleção aplicados aos ambientes no entorno da comunidade. A metodologia dos levantamentos pedológico e etnopedológico se encontra em Correia (2005). Os nomes atribuídos pela comunidade aos ambientes foram preservados na alocação das parcelas de fitossociologia, quais sejam:

a) Três (03) parcelas no ambiente denominado "areião" (A, B e C), com predomínio de solos influenciados por material de origem arenítico-quartzítico. Distante da comunidade por cerca de $3 \mathrm{a} 4 \mathrm{~h}$ de caminhada, isto é, de 8 a $10 \mathrm{~km}$, normalmente percorridos a pé ou em carro de boi. Possui a feição mais preservada na fitofisionomia de Cerrado sensu strictu.

b) Duas (02) parcelas no ambiente denominado "areiãozinho" (D e E). Também com forte influência de material de origem arenítico-quartzítico e tem feições preservadas do Cerrado sensu strictu. Entretanto,

R. Árvore, Viçosa-MG, v.33, n.5, p.957-968, 2009 
abrange uma feição não estudada, denominada "carrasco", com características típicas da transição do Cerrado para a Caatinga.

c) Duas (02) parcelas (He I) representaram o ambiente denominado localmente "chapada". As feições da vegetação são claramente distintas, com evidência de retirada de indivíduos arbóreos para fabricação de carvãovegetal, bem como de queimadas. Os solos são os Latossolos Vermelho-Amarelos Distróficos, com material de origem distinto dos demais.

d) Duas (02) parcelas foram alocadas fora da comunidade Água Boa 2, as parcelas F e G, "chapada com eucalipto", de ambiente similar ao das parcelas $\mathrm{H}$ e I, porém com plantio de eucalipto abandonado, em que o Cerrado nativo regenerava entre as linhas de cultivo.

e) A parcela J representa ambiente transicional entre a chapada e a vereda, identificado pelos informanteschave na comunidade Água Boa 2 como "pirambeira".

A área total amostrada foi de um hectare. Estudos com a mesma metodologia em Cerrados em condições similares (FELFILI et al., 1992; FELFILI e SILVA JÚNIOR, 1993; FELFILI et al., 1994, 1997) indicaram que a área amostral de 1 ha, com parcelas dispostas aleatoriamente, foi suficiente para a representatividade florística dos indivíduos arbóreos.

No interior de cada subparcela foram coletadas amostras de solo, na profundidade de 0-0,2 m. Além disso, foram amostrados os indivíduos com circunferência em nível do solo igual ou superior a 0,15 m (aproximadamente 0,048 m de diâmetro), incluindo nesse critério as ramificações emergentes de árvores tombadas e arbustos ou, ainda, árvores mortas ainda em pé. Para cada indivíduo foi tomado o perímetro no nível do solo, conforme Neri et al. (2007). O material vegetativo e, ou, reprodutivo foi coletado. Após a secagem, os espécimes foram identificados no nível de espécie ou gêneros ou famílias e, posteriormente, comparados com o material nas coleções botânicas RBR (Departamento de Botânica da UFRRJ) e JBR (Fundação Jardim Botânico do Rio de Janeiro).

\subsection{Caracterização dos solos e da vegetação}

Os atributos edáficos analisados foram: $\mathrm{pH}$ em $\mathrm{H}_{2} \mathrm{O}$; as bases $\mathrm{Ca}^{+2}, \mathrm{Mg}^{+2}, \mathrm{~K}^{+}, \mathrm{Na}^{+}$e $\mathrm{Ca}+\mathrm{Mg}$; íons da acidez do solo $\mathrm{Al}^{+3} \mathrm{e}^{+}$e $\mathrm{H}+\mathrm{Al}$; fósforo assimilável (P); carbono orgânico ( $\mathrm{C}$ org); e capacidade de troca de cátions $(\mathrm{T})$. Além dos componentes da análise granulométrica: argila total (Arg T), argila dispersa em água (Arg N), areia total (Areia), areia grossa (Ar grossa), areia fina (Ar fina), silte e grau de floculação da argila (GF). A caracterização laboratorial foi feita segundo Embrapa (1997).

Os atributos relativos à vegetação arbórea arbustiva do Cerrado foram: Densidade absoluta (ind./ ha), Área basal ( $\mathrm{m}^{2} / \mathrm{ha}$ ), Índice de Diversidade de Shannon (H') e Índice de Eqüabilidade de Pielou (J'). Os parâmetros florísticos foram estimados seguindose Vuono (2002) e os índices de diversidade de Shannon (H') e de equabilidade (J), Pielou (1975).

\subsection{Análises estatísticas}

As análises estatísticas foram baseadas em modelos não paramétricos. Os conceitos estatísticos usados foram o da mediana, do coeficiente de correlação de Pearson (r), do teste de médias de Bonferroni e das análises multivariadas de componentes principais (ACP) e de agrupamentos hierárquicos aglomerativos (AHA - dendrograma), referentes aos atributos do solo e parâmetros florísticos e fitossociológicos. A análise da correlação permitiu avaliar o grau de associação da relação linear entre as variáveis. O coeficiente de correlação de Pearson (r) foi utilizado para detectar interações lineares entre duas variáveis; o valor de $\mathbf{r}$ esteve sempre entre $-1 \mathrm{e}+1, \operatorname{com} \mathbf{r}=0$ correspondendo à nãoassociação absoluta (PIMENTEL GOMES, 1990).

O teste $t$ de Bonferroni atuou como ferramenta auxiliar na seleção de variáveis (parâmetros florísticos e fitossociológicos e atributos edáficos) que apresentaram influência significativa, dentro da comparação de cada conjunto de dados, na ACP. Os componentes principais resumiram a variação multidimensional das variáveis em um diagrama ordenado em eixos, de acordo com suas similaridades (ALVARENGA e DAVID, 1999). Consistiu em transformar um conjunto de 'p' variáveis originais $\mathrm{X} 1, \mathrm{X} 2, \ldots, \mathrm{Xp}$, pertencentes a ' $\mathrm{n}$ ' indivíduos ou populações, em um novo conjunto de variáveis, Y1, Y2, ... Yp, de dimensão equivalente, chamados de componentes principais (STRAPASSON, 2000).

A partir dos atributos citados foi criada a matriz de correlação de Pearson, no programa SAEG versão 9.0(UFV/FUNARBE, 2006). Os coeficientes de correlação foram filtrados com os seguintes critérios: nível de significância menor ou igual a 0,05 (5\%) e, 
simultaneamente, superiores ou iguais à mediana do conjunto de dados resultantes (programa Microsoft Excel XP). Tal procedimento eliminou atributos com baixas correlação e significância, resultando numa primeira seleção de atributos que, entre os avaliados, efetivamente representavam o comportamento dos ambientes. Numa segunda etapa todos os atributos foram submetidos à comparação de suas médias pelo teste de Bonferroni, com nível de significância de 0,05. Os atributos que apresentaram diferença significativa entre as médias foram selecionados e os demais excluídos da próxima etapa. Na terceira etapa foram selecionadas as variáveis que fizeram parte do conjunto interseção entre o primeiro procedimento (seleção pelo nível de significância/mediana da correlação dos atributos) e o segundo (variáveis com médias distintas pelo teste de Bonferroni). Por fim, esses atributos foram usados para elaborar os diagramas de Dendrograma e ACP, com o intuito de avaliar a extensão dos relacionamentos entre atributos e ambientes (o programa foi o XL STAT versão 7,5 da Addinsoft).

\section{RESULTADOS E DISCUSSÃO}

A partir dos atributos selecionados, foi produzida uma primeira classificação das áreas, a qual mostrou toda a similaridade entre cada subparcela dos ambientes estudados. A Figura 1 apresenta o arranjo por afinidade das subparcelas, através do dendrograma baseado na distância euclidiana entre as parcelas, calculada a partir da matriz de correlação entre as variáveis selecionadas. O padrão de agrupamento encontrado apresentou pequena variação quando outros coeficientes de medida de similaridade foram usados (e.g. distância euclidiana média, distância média absoluta, distância euclidiana

\section{Dendrograma}

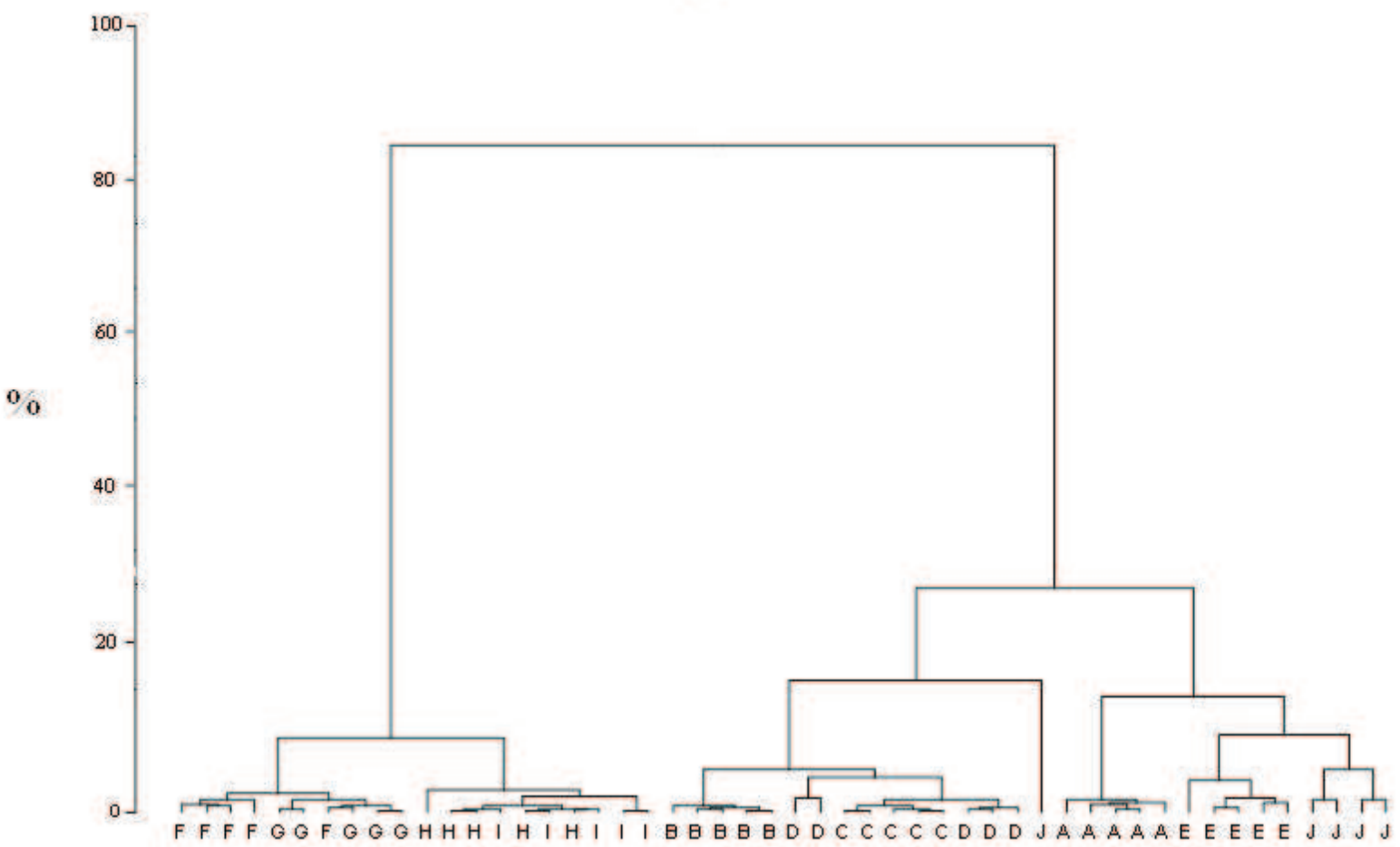

Figura 1 - Dissimilaridade por distância euclidiana entre as subparcelas amostradas no estudo fitossociológico do Cerrado sensu strictu de chapadas do entorno da comunidade Água Boa 2, Rio Pardo de Minas, MG. Legenda: Parcelas A, B e C = Areião; Parcelas D e E = Areiãozinho; Parcelas F e G = Chapada com Eucalipto; Parcelas H e I = Chapada; e $J=$ Pirambeira.

Figure 1 - Euclidian distance dissimilarity between phytosociological subplot samples of the "chapadas" cerrado sensu strictu of Água Boa 2 community surroundings, Rio Pardo de Minas, MG, Brazil. Legend: Plots A, B and C = "Areião"; Plots D and E = "Areiãozinho"; Plots F and G = "Chapada with Eucalyptus"; Plots Hand I = "Chapada"; $J=$ "Pirambeira". 
quadrática e distância relativa absoluta), indicando que o padrão é consistente (SANTOS et al., 2007). A projeção dos arcos que ligam cada subparcela ou grupos de subparcelas no eixo escalonado à esquerda do diagrama indica o ponto a partir do qual as áreas são similares entre si. Pode-se notar que dois grandes grupos são separados por dissimilaridade. O grupo que contém as parcelas $\mathrm{F}, \mathrm{G}, \mathrm{H}$ e I representa aquele ambiente onde a classe de solo predominante é o Latossolo Vermelho-Amarelo. Já o outro grande grupo diferenciado pelo dendrograma contém as parcelas A, B, C, D, E e J. Pode-se considerar que os materiais de origem dos solos dessas últimas parcelas são os mesmos (predominantemente material arenítico-quartzítico), com exceção da parcela J, que apresenta xistos entremeados.

Essa primeira separação dos ambientes foi claramente relacionada aos aspectos geológicos. O primeiro grupo de parcelas (A, B , C, D, E e J) encontra-se sob influência de recobrimentos arenosos do Terciário e da litologia do Supergrupo São Francisco/Grupo Macaúbas (précambriano), composta por quartzitos/arenitos, alguns siltitos, filitos e xistos. Estes materiais originaram solos com características influenciadas por granulometria mais grosseiras, como areia total e areia grossa, contudo ainda com variação textural. As classes de solos incluídas foram, principalmente, os Neossolos Quartzarênicos e Cambissolos Háplicos.

Já o segundo grupo (F, G, H e I), identificado através do dendrograma, recebe influência clara de recobrimentos argilo-arenosos e argilosos do Terciário e Quaternário (sedimentação muito recente). Essas condições, em geral, formam solos intemperizados, profundos e com forte agregação. Durante o levantamento dos solos foram identificados alguns perfis com microagregação, evidência do processo de formação de latossolização. Na área, esses solos foram classificados como Latossolos Vermelho-Amarelos.

\subsection{Ambientes sob influência de material arenítico- quartzítico}

Para averiguar a relação entre as subparcelas dos ambientes sob influência de material arenítico-quatzítico, foi feita uma análise de componentes principais (ACP), já que com todas as subparcelas do estudo não foi possível diferenciar os três ambientes influenciados por esse material, quais sejam: areião, areiãozinho e pirambeira. Fez-se uma seleção prévia de variáveis, utilizando o teste de Bonferroni e análise de correlação, o que resultou na inclusão de algumas variáveis (Figura 2) e exclusão de outras para o procedimento da ACP.

Em primeira análise, notou-se que os parâmetros florísticos e fitossociológicos (Tabela 1) selecionados (ind./ha, $\mathrm{m}^{2} /$ ha e $\mathrm{H}^{\prime}$ ), que foram determinantes na diferenciação dos ambientes quando consideradas todas as parcelas estudadas, não influenciaram o agrupamento quando avaliados apenas os ambientes influenciados por material arenítico-quartzítico. Esse resultado confirma a hipótese de que a vegetação dessas áreas, em conjunto, pertence a um mesmo estádio sucessional, representando os ambientes mais preservados da área estudada. Portanto, embora essas variáveis não devam ser utilizadas como indicadores na seleção de áreas de mesmo padrão de degradação/uso, elas foram eficientes para selecionar áreas com padrões distintos de sucessão ecológica.

Na ACP, o comprimento das setas é proporcional à sua importância, e os ângulos entre elas refletem as intercorrelações entre os atributos. O ângulo entre determinada seta e cada eixo de ordenação representa

Tabela 1 - Resumo das informações florísticas e fitossociológicas dos ambientes.

Table 1 - Summary of floristic and phytosociological information about the environments.

\begin{tabular}{|c|c|c|c|c|}
\hline Ambiente & Shannon $\left(\mathrm{H}^{\prime}\right)$ & Pielou (J') & $\begin{array}{c}\text { Densidade } \\
\text { Absoluta } \\
\text { (ind./ha) }\end{array}$ & $\begin{array}{c}\text { Área Basal } \\
\mathrm{m}^{2} / \mathrm{ha}\end{array}$ \\
\hline Areião & 3,01 & 0,85 & 4760 & 14,9 \\
\hline Areiãozinho & 2,72 & 0,88 & 6160 & 14,5 \\
\hline Chapada com eucalipto & 2,06 & 0,71 & 3665 & 5,9 \\
\hline Chapada & 2,48 & 0,87 & 1630 & 4,1 \\
\hline Tabuleiro & 2,09 & 0,82 & 6350 & 10,1 \\
\hline
\end{tabular}

R. Árvore, Viçosa-MG, v.33, n.5, p.957-968, 2009 
Figura 2 - Análise de Componentes Principais (ACP) de atributos em parcelas de fitossociologia, nos ambientes sob material arenítico-quartzítico, no entorno da comunidade Água Boa 2, Rio Pardo de Minas, MG. (a) dispersão das subparcelas com base nos atributos selecionados para a ACP, destacados em (b).

Figure 2 - Principal Component Analysis (PCA) of attributes of phytosociological plots of environments under sandyquartzite material, in Água Boa 2 community surroundings, Rio Pardo de Minas, MG, Brazil. (a) Dispersion of subplots based on the influence of selected attributes for PCA, detailed on (b).

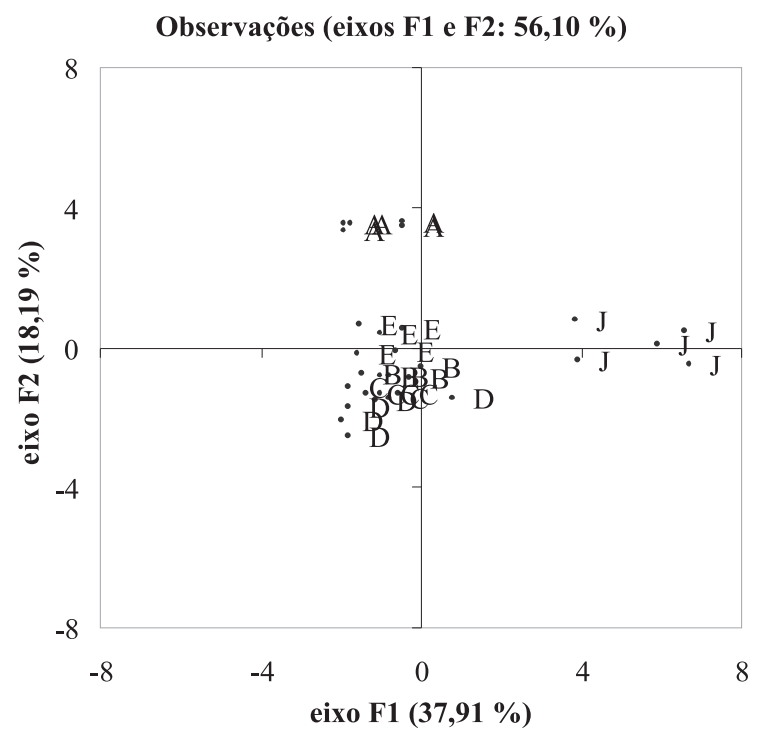

o grau de correlação com o eixo (ALVARENGAe DAVID, 1999). A Figura 2 mostra que, a partir da ACP, foi possível destacar todas as subparcelas dos ambientes representados pelas parcelas A e $\mathbf{J}$, grupo que era uniforme no agrupamento anterior. Praticamente, todos os parâmetros selecionados para a ACP correlacionaram-se positivamente com a parcela $\mathrm{J}$, com exceção ao silte, que, segundo a análise, foi o responsável pela diferenciação da parcela A. As demais parcelas analisadas agruparam-se no centro do diagrama, indicando a homogeneidade das áreas quando analisadas a partir desses atributos.

A parcela $\mathrm{J}$, embora influenciada pelo material originário das parcelas A, B, C, D e E, localiza-se distante destas, sendo separada por extensa faixa de terra sob influência de solos latossolos. Além desse fato, admite-se um material originário diferenciado para essa parcela, em função da influência de xistos, que ocorrem nessa posição do relevo na sub-bacia do rio Água Boa. Um indicador é o teor de potássio no solo, maior do que em todas as outras parcelas, marcando o efeito do material xistoso que possui maior riqueza nesse elemento.

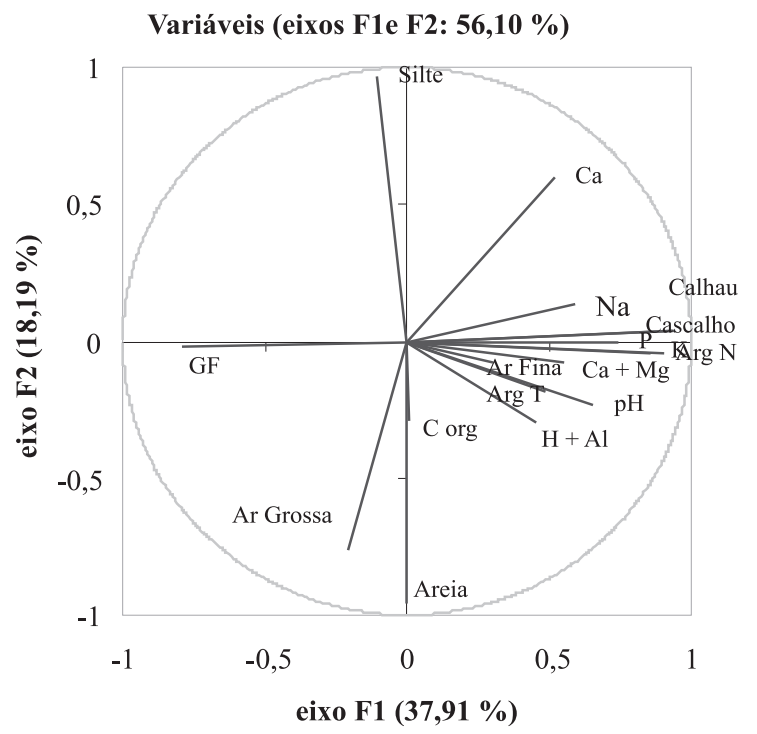

Outro fator para o destaque da parcela $\mathbf{J}$ foi a sua geomorfologia, de rampa de colúvio apresentando material inconsolidado e desagregado com complexas coberturas sedimentares, intrínsecas à dinâmica das cabeceiras de drenagem. Essa forma de paisagem é importante no controle do fluxo hidrológico, tanto na superfície quanto em subsuperfície, produzindo sedimentos que são carreados para as depressões e planícies a jusante e recebendo sedimentos e solutos advindos de áreas a montante da escarpa, na chapada. Portanto, a diferenciação desse ambiente pela ACP (Figura 2) foi influenciada tanto pelo material de origem de xistos quanto por sedimentos trazidos de cotas superiores. Outra variável importante, como indicador para a seleção de áreas com as mesmas características do ambiente de "pirambeira" (parcela J), foi o teor de cascalhos e calhaus, mais elevado nessa feição do relevo, evidenciado pelos solos Cambissolos Háplicos cascalhentos. Essas características fazem com que no ambiente de "pirambeira" ocorram espécies de grande relevância para o uso da comunidade Água Boa 2.

Uma nova aplicação da ACP foi obtida a partir de variáveis selecionadas para as parcelas A, B, C, D e E (Figura 3), de forma a explicar a variação dos ambientes

R. Árvore, Viçosa-MG, v.33, n.5, p.957-968, 2009 
edáficos com material de origem arenítico-quartzítico, excluindo as características especiais da parcela J. A Figura 3 mostrou separação melhor dos ambientes, onde os teores de silte e de Ca foram os principais responsáveis pela separação da parcela A das demais. As variáveis: Ar fina, C org. e, novamente, o silte individualizaram a parcela $\mathrm{E}$, distanciando-a dos outros ambientes analisados. O teor de silte, que influenciou o destaque das parcelas A e E, pode ter duas origens: ser resultado do intemperismo de pequenas inclusões dos siltitos entremeados ao material mais arenoso das rochas sedimentares que compõem a paisagem, ou resultar do extremo desgaste do material arenítico-quartzítico que originou os solos. A parcela B mostrou-se ligeiramente destacada das C e D, fortemente influenciada pelas variáveis Arg T e Ca+Mg e ligeiramente pela variável Ar grossa. As parcelas C e D agruparam-se em torno do eixo F1, positivamente correlacionadas com as variáveis Areia, Mg, Ar grossa, $\mathrm{H}+\mathrm{Al}$ e Corg. Podem ser observadas influências marcantes das variáveis $\mathrm{Ca}$, silte, Ar fina e $\mathrm{C}$ org sobre as áreas A e E. Os elevados teores de areia fina da parcela E expressaram o efeito da fragmentação física da fração areia fina nos altos teores de silte dessas áreas.

Em geral, a similaridade entre as áreas se dá em função de características específicas, geralmente ligadas à textura do solo em cada parcela, subparcela ou, mesmo, amostra de solo. Esse resultado é corroborado por Montenegro e Montenegro (2006), em estudo sobre a variabilidade espacial de classes texturais em Neossolos do agreste pernambucano, onde os referidos autores observaram que a não consideração da variação desses atributos nessas classes de solo pode afetar intensamente os planos de manejo agrícola das glebas.

As parcelas identificadas como "areião"e "areiãozinho" apresentaram, no entanto, características semelhantes, e considerou-se que as variáveis selecionadas, apesar da separação mostrada pela ACP, não são indicadores adequados para diferenciar esses ambientes. Adenominação local dos ambientes “areião" e "areiãozinho" foi influenciada mais pela localização, tamanho ou estrutura da vegetação nativa do que por atributos edáficos.
Observações (eixos F1 e F2: 73,15 \%)

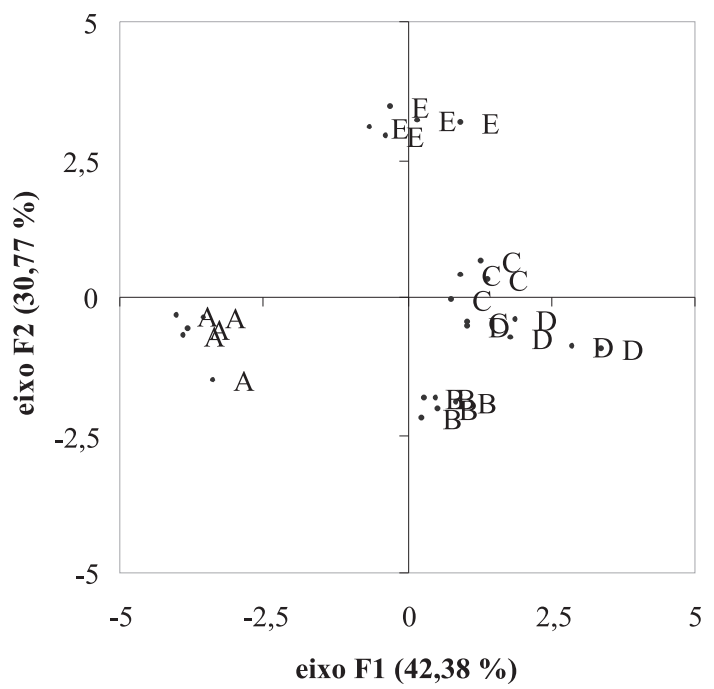

Variáveis (eixos F1 e F2: 73,15\%)

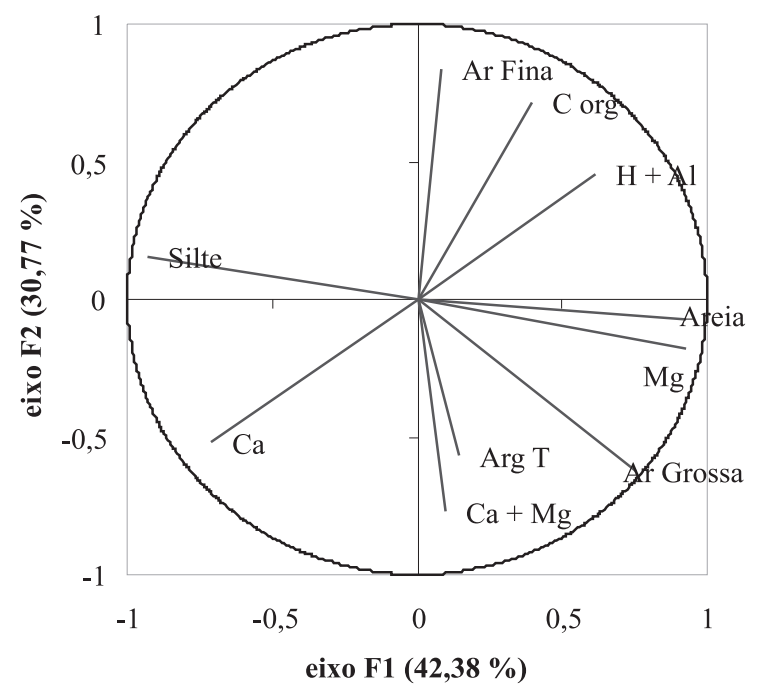

Figura 3 - Análise de Componentes Principais (ACP) de atributos em parcelas de fitossociologia, nos ambientes sob material arenítico-quatzítico, exceto na parcela J, no entorno da comunidade Água Boa 2, Rio Pardo de Minas, MG. (a) dispersão das subparcelas com base nos atributos selecionados para a ACP, destacados em (b).

Figure 3 - Principal Component Analysis (PCA) of attributes of phytosociological plots of environments under sandyquartzite material, except for J plot, of Água Boa 2 community surroundings, in Rio Pardo de Minas, MG, Brazil. (a) Dispersion of subplots based on the influence of selected attributes for PCA, detailed on (b).

R. Árvore, Viçosa-MG, v.33, n.5, p.957-968, 2009 


\subsection{Ambientes sob influência de sedimentos argilo- arenosos e argilosos}

Para estudar a variação dos ambientes sob a influência de Latossolos Vermelho-Amarelos, quais sejam as chapadas com e sem eucalipto, foi produzida uma nova ACP, somente com dados de variáveis relativas às parcelas $\mathrm{F}, \mathrm{G}$ (chapada com eucalipto), $\mathrm{H}$ e I (chapada c/ vegetação nativa, aqui chamada de somente por "chapada").

Observa-se, na Figura 4, que a ACP diferenciou perfeitamente as parcelas do ambiente de "chapada" (H e I) daquelas do ambiente de chapada com eucalipto (F e G). As variáveis que melhor se correlacionaram com a chapada com eucalipto foram: Al, número de ind./ha, Arg N, Arg T e Ar fina. Teores mais elevados de Arg $\mathrm{N}$ nesse ambiente podem indicar processos erosivos mais intensos devido ao manejo do solo antes do abandono das glebas de eucalipto. Isso, principalmente, no preparo da área para o plantio, onde a limpeza da vegetação anterior e a exposição do solo aumentaram o impacto direto das gotas de chuvas sobre os agregados do solo. Como resultado, aumentou a erosão hídrica e a perda de coloides e solutos por escoamento superficial e enxurrada, com redução da fertilidade natural (GUERRA, 1999). Na chapada com eucalipto, a ACP dividiu totalmente as parcelas $\mathrm{F}$ e G, utilizadas para caracterização desse ambiente. A linha que divide as duas parcelas é, na ACP, exatamente a linha do eixo F1, e os parâmetros de maior correlação positiva com a parcela $\mathrm{G}$ foram $\mathrm{N}^{\circ}$. ind. e Ar fina. Tal fato indicou que a parcela $\mathrm{F}$ foi disposta em ambiente cujo manejo de implantação da cultura foi mais degradante que o da parcela $G$, como consequência das práticas citadas.

Já nas parcelas em ambiente de "chapada" pode-se observar grande influência das variáveis $\mathrm{Na}, \mathrm{K}, \mathrm{pH}$, $\mathrm{C}$ org, Ar grossa, Areia, GF e o índice de equabilidade de Pielou (J'). Esses resultados indicaram que o ambiente de "chapada" encontrava-se em melhor estádio de conservação do que o da chapada com eucalipto (parcelas F e G), uma vez que na "chapada" (parcelas H e I) foram observadas correlações positivas com variáveis como GF, Corg, pH, K e J', evidenciando teores mais elevados dessas variáveis nessas áreas.
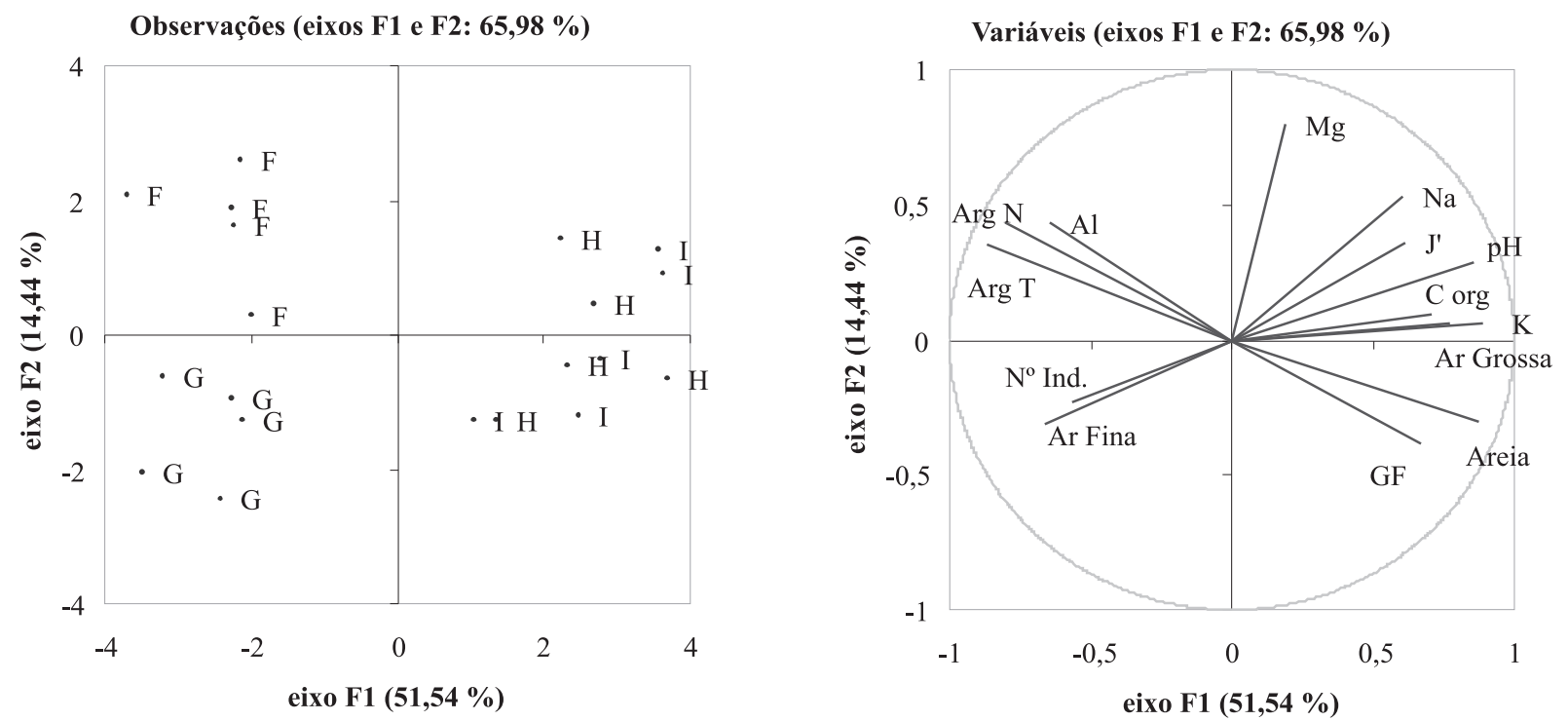

Figura 4 - Análise de Componentes Principais (ACP) de atributos em parcelas de fitossociologia nos ambientes sob materiais argilo-arenosos e argilosos, no entorno da comunidade Água Boa 2, Rio Pardo de Minas, MG. (a) dispersão das subparcelas foi com base nos atributos selecionados para a ACP, destacados em (b).

Figure 4 - Principal Component Analysis (PCA) of attributes of phytosociological plots of environments under clay-sandy and clayey materials, of Água Boa 2 community surroundings, in Rio Pardo de Minas, MG, Brazil. (a) Dispersion of subplots based on the influence of selected attributes for PCA, detailed on (b). 
A correlação com o GF indicou maior estabilidade dos agregados e, ou, maior proteção do solo contra o impacto da chuva. Os maiores teores de C org mostraram que o ambiente, mesmo sob o efeito de manejo exploratório e desordenado, pode acumular C no solo e garantir os benefícios da matéria orgânica do solo, como elevação da CTC e maior adsorção de bases. Por fim, a correlação com o J' indica que, nos ambientes de "chapada", mesmo diante da retirada da vegetação arbórea para fabricação de carvão e uso com pastagens extensivas, com queimas sazonais, a vegetação possuiu maior grau de uniformidade, favorecendo o processo sucessional e garantindo novos ciclos de corte da vegetação sobre regime de pousio.

\section{CONCLUSÕES}

A análise de componentes principais e a de agrupamentos hierárquicos aglomerativos, auxiliados pelo método proposta de análise de correlação e pelo teste de Bonferroni, foram capazes de discriminar os ambientes representados pelo levantamento fitossociológico. Portanto, a análise multivariada pode ser aplicada na seleção de variáveis relevantes na caracterização e no planejamento de uso sustentável dos ambientes estudados.

Os padrões de solo e vegetacionais identificados pelos agricultores refletiram, em geral, as variações nos atributos edáficos e parâmetros florísticos e fitossociológicos, validando, assim, a informação etnocientífica como apoio para distinção de ambientes.

Entre os atributos e parâmetros avaliados, em geral os aspectos geológicos, litologia e natureza dos sedimentos; os parâmetros florísticos e fitossociológicos, densidade absoluta, área basal e o índice de diversidade; e as frações granulométricas foram determinantes na diferenciação dos ambientes.

\section{AGRADECIMENTOS}

Ao Conselho Nacional de Desenvolvimento Científico e Tecnológico (CNPq), ao World Wildlife Foundation (WWF), ao Centro de Agricultura Alternativa do Norte de Minas (CAA-NM), ao Sindicato dos Trabalhadores Rurais de Rio Pardo de Minas e ao Engenheiro Agrônomo e M. Sc. Júlio César de Lucena Araújo, pela grande contribuição.

\section{REFERÊNCIAS}

ACCIOLY, L. J. O.; OLIVEIRA, M. A. J.

Indicadores de processos de desertificação. In: ROMEIRO, A. R. Avaliação e contabilização de impactos ambientais. Campinas: Unicamp; São Paulo: Imprensa Oficial do Estado de São Paulo, 2004. p.123-139.

ALVARENGA, M. I. N.; DAVIDE, A. C. Características físicas e químicas de um Latossolo Vermelho-Escuro e a sustentabilidade de agroecossistemas. Revista Brasileira de Ciência do Solo, v.23, n.4, p.933-942, 1999.

ALVES, V. E. L. A mobilidade sulista e a expansão da fronteira agrícola brasileira. Agrária, n.2, p.40-68, 2005.

BRITO, J. O.; BARRICHELO, L. E. G.; SEIXAS, F. Análise da produção energética e de carvãovegetal de espécies de eucalipto. IPEF, n.23, p.53-56, 1983.

CORREIA, J. R. Pedologia e conhecimento local: proposta metodológica de interlocução entre saberes construídos por pedólogos e agricultores em área de Cerrado em Rio Pardo de Minas, MG. 2005. 234f. Tese de Doutorado Universidade Federal Rural do Rio de Janeiro, Seropédica, 2005.

CORREIA, J. R. et al. Relações entre o conhecimento de Agricultores e de pedólogos sobre solos: estudo de caso em Rio Pardo de Minas, MG. Revista Brasileira de

Ciência do Solo, v.31, n.5, p.1045-1057, 2007.

DAYREL, C. A. Geraizeiros e

biodiversidade no norte de Minas: a contribuição da agroecologia e da etnoecologia nos estudos dos agroecossistemas tradicionais. Hanolver, Espanha, Universidade Internacional de Andalucia, 1998. 180p.

DIAS, B. F. S. Cerrados: uma caracterização. In: DIAS, B. F. S. (Coord.) Alternativas de desenvolvimento dos Cerrados: manejo e conservação dos recursos naturais renováveis. Brasília: Fundação Pró Natureza, 1996. p.11-25. 
DREGNE, H. E. Soils of arid regions. Amsterdan: Elsevier Scientific Publishing Company, 1976. 237p.

EMPRESA BRASILEIRA DE PESQUISA AGROECUÁRIA - EMBRAPA. Centro Nacional de Pesquisa de Solos. Manual de métodos de análise de solos. Rio de Janeiro: 1997. 212p.

EMPRESA BRASILEIRA DE PESQUISA AGROECUÁRIA - EMBRAPA. Levantamento exploratório - reconhecimento de solos do norte de Minas Gerais (área de atuação da SUDENE). Convênio de mapeamento de solos. Recife: 1979. 407p.

FELFILI, J. M.; SILVA JÚNIOR, M. C. A comparative study of cerrado (sensu strictu) vegetation in Central Brazil. Journal of Tropical Ecology, v.9, n.3, p.277-289, 1993.

FELFILI, J. M. et al. Projeto biogeografia do bioma cerrado: vegetação e solos. Cadernos de Geociências, n.12, p.75-166, 1994.

FELFILI, J. M. et al. Análise comparativa da florística e fitossociologia da vegetação arbórea do Cerrado sentido restrito na Chapada da Pratinha, DF-Brasil. Acta Botanica

Brasilica, v.6, n.2, p.27-46, 1992.

FELFILI, J. M. et al. Comparação florística e fitossociológica do cerrado nas chapadas Pratinha e dos Veadeiros. In: LEITE, L.; SAITO, C. H. (Eds.). Contribuição ao conhecimento ecológico do cerrado. Brasília: Universidade de Brasília, 1997.

FERREIRA, S. J. F. et al. Soil water storage in an upland forest after selective logging. In Central Amazonia. Revista Brasileira de Ciência do Solo, v.28, n.1, p.59-66, 2004.

GRIFFTH, J. J.; TOY, T. J. O modelo físico-social da recuperação ambiental. Brasil Mineral, v.22, n.242, p.166-174, 2005.

GUERRA, A. J. T. O início dos processos erosivos nas encostas. In: GUERRA, A. J. T.; SILVA, A. S.; BOTELHO, R. G. M. Erosão e conservação dos solos - conceitos, temas e aplicações. Rio de Janeiro: Bertrand Brasil, 1999. p.17-49.
MACHADO, R. B. et al. Estimativas de perda da área do Cerrado Brasileiro. Relatório técnico não publicado. Conservação Internacional, Brasília, 2004. 25p. Disponível em <http:// arruda.rits.org.br/oeco/reading/oeco/reading/pdf/ cerrado.pdf $>$ acessado em 14 de abril de 2009.

MIRANDA, E. E. Brasil visto do espaço: Minas Gerais. Campinas: Embrapa Monitoramento por Satélite, 2003. CD ROM.

\section{MONTENEGRO, A. A. A.; MONTENEGRO, S. M. G.}

L. Variabilidade espacial de classes de textura, salinidade e condutividade hidráulica de solos em planície aluvial. Revista Brasileira de Engenharia Agrícola e Ambiental, v.10, n.1, p.30-37, 2006.

NERI, A. V. et al. Análise da estrutura de uma comunidade lenhosa em área de cerrado sensu stricto no município de Senador Modestino Gonçalves, norte de Minas Gerais, Brasil. Revista Árvore, v.31, n.1, p.123-134, 2007.

PIELOU, E. C. Ecological diversity. New York: John Willey \& Sons, 1975. 165p.

PIMENTEL GOMES, F. Curso de estatística experimental. 13.ed. Piracicaba: Nobel, 1990. 468p.

RIBEIRO, J. F.; WALTER, B. M. T. As matas de galeria no contexto do bioma Cerrado. In: RIBEIRO, J. F.; FONSECA, C. E. L.; SOUSA-SILVA, J. C.

Cerrado: caracterização e recuperação de Matas de Galeria. Planaltina: Embrapa/Ministério da Agricultura, Pecuária e Abastecimento, 2001. p.29-45.

SANTOS, R. M. et al. Riqueza e similaridade florística de oito remanescentes florestais no norte de Minas Gerais, Brasil. Revista Árvore, v.31, n.1, p.135144, 2007.

SEBRAE-MG. Diagnóstico municipal: Rio Pardo de Minas. Montes Claros: 2003. CD ROM (Programa Grande Sertão).

SILVA JUNIOR, M. C. Guia de campo: 100 árvores do cerrado. Brasília: Rede de Sementes do Cerrado, 2005. 278p.

UFV/FUNARBE. SAEG: Sistema de análise estatística geral. Viçosa, MG: 2006.

R. Árvore, Viçosa-MG, v.33, n.5, p.957-968, 2009 
STRAPASSON, E.; VENCOVSKY, R.; BATISTA, L. A. R. Seleção de descritores na caracterização de germoplasma de Paspalum sp. por meio de componentes principais. Revista Brasileira de Zootecnia, v.29, n.2, p.373-381, 2000.
VUONO, Y. S. Inventario fitossociológico. In: SILVESTRE, L. S.; ROSA, M. M. T. Manual metodológico para estudos botânicos na mata atlântica. Seropédica, EDUR-UFRRJ, 2002. p.51-65.

R. Árvore, Viçosa-MG, v.33, n.5, p.957-968, 2009 